\title{
Editorial: RAMIRAN 2017: Sustainable Utilisation of Manures and Residue Resources in Agriculture
}

\author{
Tom Misselbrook ${ }^{1 *}$, Claudia Wagner-Riddle ${ }^{2}$, Karl Richards $^{3}$, Gary Lanigan ${ }^{3}$, \\ William Burchill ${ }^{3}$ and Francisco Salazar ${ }^{4}$ \\ ${ }^{1}$ Rothamsted Research, Okehampton, United Kingdom, ${ }^{2}$ School of Environmental Sciences, University of Guelph, Guelph, \\ ON, Canada, ${ }^{3}$ Teagasc, Johnstown Castle, Wexford, Ireland, ${ }^{4}$ Instituto de Investigaciones Agropecurarias, INIA Remehue, \\ Osorno, Chile
}

Keywords: organic residues, livestock manure, manure management, digestate, circular economy

\section{Editorial on the Research Topic}

\section{RAMIRAN 2017: Sustainable Utilisation of Manures and Residue Resources in Agriculture}

The recycling of organic residues deriving from on-farm (e.g., livestock manure) or off-farm (e.g., sewage sludge, industrial by-products) is a central part of the circular economy toward developing more sustainable food production systems (e.g., EC, 2014). However, the safe, effective, and efficient use of organic "waste" streams as resources for nutrient provision and soil improvement in agricultural systems require several challenges to be addressed, summarized by Bernal (2017) as (i) to improve nutrient availability and soil cycling; (ii) to develop technologies for nutrient re-use; (iii)

OPEN ACCESS

Edited and reviewed by: Maria Pilar Bernal, Spanish National

Research Council, Spain

${ }^{*}$ Correspondence: Tom Misselbrook

tom.misselbrook@rothamsted.ac.uk

Specialty section:

This article was submitted to Waste Management in

Agroecosystems,

a section of the journal

Frontiers in Sustainable Food Systems

Received: 30 August 2019 Accepted: 09 September 2019 Published: 24 September 2019

Citation:

Misselbrook T, Wagner-Riddle C, Richards K, Lanigan G, Burchill W and Salazar F (2019) Editorial: RAMIRAN

2017: Sustainable Utilisation of Manures and Residue Resources in Agriculture

Front. Sustain. Food Syst. 3:80. doi: 10.3389/fsufs.2019.00080 to reduce contaminants and improve food safety; (iv) to mitigate environmental emissions; and (v) to enhance soil health and function. Addressing these challenges needs multidisciplinary research within a whole systems context.

The "Recycling of Agricultural, Municipal and Industrial Residues to Agriculture Network" (RAMIRAN) is a research and expertise network focusing on environmental, hygienic, and agronomic issues associated with the use of livestock manure and other organic residues in agriculture, and as such is well-positioned to address these grand challenges, and indeed has been doing so for some years (Misselbrook et al., 2012). The network evolved in 1996 as an expansion of the previous more narrowly focused FAO Animal Waste Network, initially as a predominantly European network but more recently with a much more global make-up and remit. The main aims of RAMIRAN are to promote the exchange of methodologies, materials, and processes; to progress knowledge relating to agronomic, environmental, and hygienic aspects of organic residue recycling in agriculture; to identify research priorities and initiate innovative collaborative activities that make use of the synergies within the international network. One of the main activities of RAMIRAN is to hold a regular international scientific conference. The papers in this Research Topic derive from the 17th International conference, RAMIRAN 2017, held in Wexford, Ireland in September 2017, with contributions at the conference from over 30 countries representing 6 continents.

Livestock manure is a key organic resource for re-use in agriculture, although the increasing specialization and spatial disconnect between livestock and arable production in many parts of the world, together with the comparatively low cost and ease of use of synthetic fertilizers, has resulted in this resource not being effectively utilized and often treated as a waste. A good understanding therefore of the types, quantities, and composition (particularly of plant available nutrients) for this resource are an important first step in planning for their improved utilization at a regional and local scale. There are challenges in collecting accurate data on this at the national scale, as discussed by Luostarinen et al., who provide a case study of a model approach for Finland and argue for a greater international harmonization in approaches. An example of a national data 
set is given by Loyon who provides statistics on the types of manure and practices used to store and land-apply the 120 million tons of manure produced per year by cattle, pigs, and poultry in France. Land availability, suitability, and requirement for crop nutrients are also key factors in the planning of effective organic resource utilization and Gubert et al. present a GIS-based approach to the management of digestate spreading on Alpine hay meadows which could have much broader applicability. A manure management survey on a broader regional basis, for South America, specifically for dairy manure was undertaken by Herrero et al. who highlight the generally positive perception of dairy manure as a good fertilizer but also the barriers to achieving effective management. The importance of policy and other stakeholder interventions to improve nutrient use efficiency and reduce environmental pollution is also discussed.

The impact of livestock diet on manure composition, and $\mathrm{N}$ excretion in particular, is important to predict subsequent impacts on nitrogen losses and transformations through the manure management chain. The ability to model this impact at the national and farm-scale is crucial both for providing accurate estimates in national emission inventories and for assessing potential dietary strategies for emission mitigation. Bannink et al. describe an improved approach to estimating nitrogen excretion in dairy cows, and in particular the urinary nitrogen excretion, in the Dutch ammonia emission inventory based on a Tier 3 method for enteric methane prediction. A range of dietary strategies for dairy cows and their impact on nitrogen excretion and subsequent nitrogen utilization and losses at the farm scale were assessed by Dijkstra et al., who present developments to an existing model to provide better representation of manure nitrogen availability to crops. Varma et al. demonstrate, however, the unintended consequences that may occur through dietary manipulation, reporting an increase in the emissions of odorous volatile organic compounds from manure from calves fed a diet supplemented with pomegranate peel extract intended to improve calf health.

Recycling of nutrients through the direct excretal returns of grazing animals reduces the requirement for additional nutrient application to the pasture, but the concentration of nutrients, nitrogen in urine patches in particular, poses a risk of losses to the environment (Selbie et al., 2015). A novel remote sensing method for mapping the spatial distribution of urine patches is described by Maire et al. which could be of great use in assessing the influence of different grazing management strategies or other interventions on predicted nitrogen losses and loss risk mapping.

Anaerobic digestion of organic residues as an energy source, waste treatment process and source of potentially valuable organic fertilizer has increased greatly in recent years. For economic viability, the gas yield of the process is of great importance and as described by Chiariotti and Crisà, who investigated specific inoculum for hydrogen production from livestock by-products, are influenced by the archeal and bacterial community composition. Improving the agronomic benefits of the resulting digestate from the anaerobic digestion process through acidification (Sánchez-Rodríguez et al.) or solids separation (Ehmann et al.) are discussed as is the benefit of summer fertigation of dairy slurry compared with autumn injection to cropping systems at risk of nitrate leaching (Gamble et al.). The issue of potential increased heavy metal availability and uptake by plants following applications of digestate to crops is addressed by Dragicevic et al., who report that application of biogas digestates had little effect on plant metal uptake or crop quality.

While livestock manure and digestates represent the majority of organic residue returns to land, there are a range of other materials which can potentially be used. One barrier to their uptake is heterogeneity in both the material itself and in the application of it to the land, giving less confidence in the agronomic benefits compared with the application of synthetic fertilizers. Technologies to improve the consistency of the materials and the precision of their application are therefore required. Toward this, Delin et al. assessed the optimum precise placement of pelleted meat bone meal for a spring oats crop, which showed significant yield benefits over surface broadcast application. Another potential barrier is the concern regarding safe use of materials on crops for either animal feed or human food production. Source separated human urine represents a valuable source of major and micronutrients for application to crops (Vinneras and Jonsson, 2002), but there are concerns regarding the presence of pharmaceuticals and hormones in human urine. Results from the field study reported by Viskari et al. using human urine as a fertilizer for barley, suggest that source separated urine can be safely used as a fertilizer, with no pharmaceuticals or hormones detected in soil or barley grain, despite being present in the applied urine.

Risk of contamination is also a concern addressed in papers by Ashekuzzaman et al., investigating the potential transfer of $E$. coli from slurry and biosolids application to grazing land, and Nolan et al., studying the survival and fate of pathogens through anaerobic digestion. At a broader scale, Sasakova et al. consider the risks of transfer of microbial pathogens from agricultural activities to surface and ground waters in a catchment in Slovakia and the appropriateness of current regulations.

Finally, the importance of soil health in enabling good nutrient use efficiency and the potential impacts that organic residue applications may have on this are addressed by Bhogal et al., who show that the quantity and quality of the material applied influence the level of improvement in soil organic carbon content, and by association soil biological and physical properties.

Undoubtedly there is still much research to be conducted in this area and the relevance of RAMIRAN is as great now as it ever was in addressing the challenges of sustainable recycling of organic resources to agriculture, of enhancing the circular economy and minimizing the environmental footprint of our food production systems.

\section{AUTHOR CONTRIBUTIONS}

TM, CW-R, KR, GL, WB, and FS all contributed to the writing of this editorial. 


\section{ACKNOWLEDGMENTS}

The authors would like to thank all contributors to this Research Topic, particularly the many reviewers who helped to improve

\section{REFERENCES}

Bernal, M. P. (2017). Grand challenges in waste management in agroecosystems. Front. Sustain. Food Syst. 1:1. doi: 10.3389/fsufs.201 7.00001

EC (2014). "Towards a circular economy: a zero waste programme for Europe" in Communication from the Commission to the European Parliament, the Council, the European Economic and Social Committee and the Committee of the Regions (COM) (Brussels), 398.

Misselbrook, T. H., Menzi, H., and Cordovil, C. (2012). Preface - Recycling of organic residues to agriculture: agronomic and environmental impacts. Agric. Ecosyst. Environ. 160, 1-2. doi: 10.1016/j.agee.201 2.08.003

Selbie, D. R., Buckthought, L. E., and Shepherd, M. A. (2015). The challenge of the urine patch for managing nitrogen in grazed pasture systems. Adv. Agron. 129, 229-292. doi: 10.1016/bs.agron.2014.09.004 the quality of the scientific papers, and to the organizers of the RAMIRAN 2017 conference in Wexford in September 2017 from which these papers derive. The financial sponsorship received for RAMIRAN 2017 is gratefully acknowledged.

Vinneras, B., and Jonsson, H. (2002). The performance and potential of fecal separation and urine diversion to recycle plant nutrients in household wastewater. Bioresour. Technol. 84, 275-282. doi: 10.1016/S0960-8524(02)00054-8

Conflict of Interest: The authors declare that the research was conducted in the absence of any commercial or financial relationships that could be construed as a potential conflict of interest.

Copyright (C) 2019 Misselbrook, Wagner-Riddle, Richards, Lanigan, Burchill and Salazar. This is an open-access article distributed under the terms of the Creative Commons Attribution License (CC BY). The use, distribution or reproduction in other forums is permitted, provided the original author(s) and the copyright owner(s) are credited and that the original publication in this journal is cited, in accordance with accepted academic practice. No use, distribution or reproduction is permitted which does not comply with these terms. 